\title{
Characteristics of COVID-19 in cancer patients: a cross-sectional study in Peru
}

\author{
Eduardo Payet ${ }^{1}$, Joan Perez ${ }^{2}$, Gustavo Sarria ${ }^{3}$, Silvia Neciosup ${ }^{4}$, Francisco Berrospi ${ }^{1}$, Sheila Vilchez ${ }^{5}$, Jorge Dunstan ${ }^{5}$, Ronald Perez $^{6}$, \\ Mauricio Vassallo ${ }^{7}$, Santiago Salgado 7 , Nanto Caparachín ${ }^{8}$, Joseph A Pinto ${ }^{9}$ and Alexis Holguin ${ }^{10}$
}

\begin{abstract}
${ }^{1}$ Departamento de Cirugía en Abdomen, Instituto Nacional de Enfermedades Neoplásicas, Av Angamos 2520, Surquillo, Lima 34, Peru ${ }^{2}$ Departamento de Cirugía Ginecológica, Instituto Nacional de Enfermedades Neoplásicas, Av Angamos 2520, Surquillo, Lima 34, Peru ${ }^{3}$ Departamento de Radioterapia, Instituto Nacional de Enfermedades Neoplásicas, Av Angamos 2520, Surquillo, Lima 34, Peru ${ }^{4}$ Departamento de Medicina Oncológica, Instituto Nacional de Enfermedades Neoplásicas, Av Angamos 2520, Surquillo, Lima 34, Peru ${ }^{5}$ Departamento de Cirugía en Mamas y Tejidos Blandos, Instituto Nacional de Enfermedades Neoplásicas, Av Angamos 2520, Surquillo, Lima 34, Peru ${ }^{6}$ Departamento de Medicina Crítica, Instituto Nacional de Enfermedades Neoplásicas, Av Angamos 2520, Surquillo, Lima 34, Peru ${ }^{7}$ Escuela Profesional de Medicina, Universidad Peruana de Ciencias Aplicadas, Av Prolongación Primavera 2390, Lima 15023, Peru ${ }^{8}$ Unidad de Gestión de Riesgos y Seguridad del Paciente, Instituto Nacional de Enfermedades Neoplásicas, Av Angamos 2520, Surquillo, Lima 34, Peru ${ }^{9}$ Escuela Profesional de Medicina Humana, Filial Ica, Universidad Privada San Juan Bautista, Carretera Panamericana Sur Km 300, Ica, 11004, Peru

${ }^{10}$ Departamento de Infectología, Instituto Nacional de Enfermedades Neoplásicas, Av Angamos 2520, Surquillo, Lima 34, Peru
\end{abstract}

\section{Abstract}

Background: Cancer patients are at higher risk of infection and severity of Coronavirus Disease-19 (COVID-19). Management of patients infected by severe acute respiratory syndrome coronavirus 2 (SARS-CoV-2) is challenging due to the scarce scientific information and treatment guidelines. In this work, we present our Institutional experience with our first 100 patients with oncological malignancies and COVID-19.

Patients and methods: We conducted a cross-sectional study of the first 100 patients hospitalised at the Instituto Nacional de Enfermedades Neoplasicas (Lima, Peru) who were positive for SARS-CoV-2 by reverse transcriptase (RT)-PCR during the period 30 March to 20 June. Clinicopathological variables of the oncological disease as well as risk factors, management and outcomes to COVID-19 were evaluated.

Results: The mean age was 43.5 years old (standard deviations: \pm 24.8 ) where $57 \%$ were male patients. In total, $44 \%, 37 \%$ and $19 \%$ were adult patients bearing solid tumours, adults with haematologic malignancies and paediatric patients, respectively. Hypertension was the most frequent comorbidity (23\%) followed by chronic lung disease (10\%). COVID-19-associated symptoms included cough (65\%), fever (57\%) and dyspnoea (56\%). Twelve percent of patients were asymptomatic. Nosocomial infections were more frequent in paediatric patients $(84.2 \%)$ than in adult patients (16.0\%). Patients with uncontrolled oncological disease were most frequent (72\%). Anaemia was present in $67 \%$ of patients, $68 \%$ had lymphopenia, $62 \%$ had ferritin value $>500 \mathrm{mcg} / \mathrm{L}, 85 \%$ had elevated lactate dehydrogenase $(\mathrm{LDH}), 83 \% \mathrm{D}$-dimer $>500$ $\mathrm{ng} / \mathrm{mL}$ and $80 \%$ C-Reactive Protein $>8 \mathrm{mg} / \mathrm{L}$. The most common complication was acute respiratory failure (42\%). Overall fatality rate was $39 \%$ where the main cause of mortality was acute respiratory distress syndrome (64.1\%).

Conclusion: Paediatric patients had better outcomes than adult populations, and a high number of asymptomatic carriers and nosocomial infection, early diagnosis are recommended. Considering oncological treatments 30 days before COVID-19 diagnosis, our data did not reveal an increased mortality.

Keywords: COVID-19, SARS-CoV-2, cancer, mortality
Correspondence to: Eduardo Payet

Email: edpayet@gmail.com

ecancer 2021, 15:1246

https://doi.org/10.3332/ecancer.2021.1246

Published: $10 / 06 / 2021$

Received: 26/11/2020

Publication costs for this article were supported by ecancer (UK Charity number 1176307).

Copyright: (c) the authors; licensee ecancermedicalscience. This is an Open Access article distributed under the terms of the Creative Commons Attribution License (http:// creativecommons.org/licenses/by/3.0), which permits unrestricted use, distribution, and reproduction in any medium, provided the original work is properly cited. 


\section{Highlights}

- A 39\% mortality rate was observed where mortality in the group of adult patients was $50 \%$.

- Acute Respiratory Distress Syndrome (ARDS) is the main cause of death in oncological patients with COVID-19.

- The major origin of SARS-CoV-2 infection in paediatric patients with cancer is nosocomial.

\section{Introduction}

At the end of December 2019, 29 cases of pneumonia of unknown origin detected in Wuhan (China) were reported to the World Health Organization (WHO) [1, 2]. Further research identified the aetiological agent as a new coronavirus named later severe acute respiratory syndrome coronavirus 2 (SARS-CoV-2) and the causing disease as Coronavirus Disease-19 (COVID-19) [3, 4]. As the disease spreads across the globe, it was categorised as a pandemic on 11 March 2020 [3]. As of 24 October, more than 42 million of cases were diagnosed and 1.1 million of deaths have been reported worldwide (mortality rate of $2.7 \%$ ) [5].

In Peru, the first case of COVID-19 was confirmed on 6 March 2020, in a Peruvian citizen who came from Europe. In the following months, SARS-CoV-2 spreads quickly in the country where some sociodemographic variables had a key role in the dissemination of this disease [6, 7]. As of October 2020, the Ministry of Health of Peru reported more than 883,000 cases (77.4\% detected by rapid tests) and 34,000 deaths were reported (fatality rate of $3.85 \%$ ). In total, $69.9 \%$ of deceased patients were older than 60 years old [8].

Cancer patients have an increased susceptibility and vulnerability to SARS-CoV-2 [9, 10]. A recent meta-analysis by Kong et al [11] showed that the incidence of severe illness in COVID-19 patients with cancer is $34 \%$ compared to $14 \%$ in cancer free individuals. On the other hand, the mortality rate was $20 \%$ compared to $0.05 \%$ in patients without cancer [11]. This increase in the fatality rate quickly positioned COVID-19 as a serious public health problem with life threatening complications for cancer patients [12]. In addition, cancer patients at Wuhan were 2.31 times more likely to contract the infection than non-cancer patients [13]. Cancer patients are twice more likely to have severe or critical symptoms, to need invasive mechanical ventilation (IMV) and consequently to be admitted to an intensive care unit (ICU) and eventually die [10].

In general, cancer patients have a worse prognosis and deteriorate quicker than a patient without cancer; moreover, SARS-CoV-2 infected cancer patients have a lower prevalence of IgG antibodies and they have a high risk to acquire a nosocomial infection of COVID-19 and a higher risk of death $[10,14,15]$.

The COVID-19 pandemic has changed the global landscape of cancer management as well as for other chronic diseases where patients from developing countries and patients with scarce resources are the most affected. This current situation forces us to better understand the real impact of COVID-19 in our oncologic patients, as well as learn how COVID-19 behaves in cancer patients and how to improve the management of these patients and with the forthcoming economic crisis, our decision making in public health.

In this study, we aim to describe the features of COVID-19 in cancer patients who were hospitalised at our Institution as well as the treatment strategies and outcomes in these patients.

\section{Patients and methods}

\section{Study design and patient's population}

We conducted a retrospective, descriptive and cross-sectional study to describe the clinicopathological characteristics, risk factors, treatments and outcomes of cancer patients diagnosed with COVID-19 infection. We included paediatric and adult cancer patients hospitalised (at least 24 hours) at the Instituto Nacional de Enfermedades Neoplásicas (INEN) during the period 30 March-20 June 2020 and positive results for RNA detection of SARS-CoV-2 by RT-PCR. 


\section{Variables and outcomes}

We evaluated baseline cancer-related variables including age (at COVID-19 diagnosis), sex, comorbidities, smoking status, type of cancer, clinical stage, control of oncological disease (controlled disease was defined as absence of cancer progression or recurrence after treatment), previous treatment for cancer (prior 30 days). COVID-19-related variables included initial signs and symptoms, severity of COVID-19 (as described initially by the WHO [16]), origin of infection (according to qualified by Wang et al [17]), main findings on computed tomography (CT) study, percentage of lung involvement as evaluated in the CT study (according to Bernheim et al [18]) and results of bronchioalveolar lavage (BAL), blood and urine culture. Variables related to the management of COVID-19 disease included the maximum oxygen requirement (We define low oxygen requirement as the use of binasal cannula and simple mask, and high oxygen requirement as the use of reservoir mask), admission to the ICU, pharmacological treatment for COVID-19, antibiotic treatment to companion infections, drug-related toxicities. Finally, COVID-19 assessed outcomes included complications, clinical outcome, fatality rate and cause of death.

\section{Statistical analysis}

Due to the small sample size, we conducted only descriptive studies. For quantitative variables, means and standard deviations (SD) were estimated. For qualitative variables, we calculated frequencies and percentages.

\section{Ethical considerations}

This study was reviewed and approved by the Institutional Review Board (IRB) of the INEN (approval 049-2020-CRPI-DI-DICON/INEN). The use of an informed consent was waived by the IRB.

\section{Results}

\section{Patient demographic and tumour characteristics}

During the study period, 100 patients met our eligibility criteria where $44 \%$ of patients were adults with solid tumours, $37 \%$ were adults with haematological malignancies and $19 \%$ were paediatric cancers. The mean age was 43.5 years old (SD: \pm 24.8 ; range: 18 months to 80 years old); in paediatric patients, the mean age was 5 years old (SD: \pm 4.4 ), while in adults it was 52.4 years old (SD: \pm 17.6 ). Fifty-seven percent of patients were male. Regarding to comorbidities, $23 \%$ of patients had hypertension, $10 \%$ chronic lung disease, $8 \%$ obesity and $6 \%$ diabetes. Eight percent of patients were smokers. The most frequent type of cancers was leukaemia (28\%), lymphomas (19\%), breast and soft tumours (12\%), among others. In total, 40\% of patients received chemotherapy, $7 \%$ surgery and 4\% radiotherapy within 30 days prior to COVID-19 diagnosis. A detailed description of the patient's characteristics is presented in Table 1.

\section{Clinical presentation of COVID-19}

Cough, fever, dyspnoea and tachypnoea were the most frequent initial signs and symptoms (65\%, 57\%, 56\% and 56\%, respectively). Regarding WHO COVID-19 interim guidance, severity was assessed as 32\% were mild; 33\%, moderate; $17 \%$, severe and $18 \%$ were critical patients [16]. Overall, $71 \%$ of infections were in the community and $29 \%$ were nosocomial infections. Interestingly, $84.2 \%$ of COVID-19 infections in paediatric patients were acquired during the hospitalisation. In patients with chest-CT evaluation, main findings were grounded-glass opacities (55\%) and consolidative pulmonary opacities (32\%). Twenty-four percent of cases had a lung involvement > 51\%. A more detailed description of the COVID-19 presentation is presented in Table 2.

The mean concentration of the main laboratory parameters was C-reactive, $173.6 \mathrm{mg} / \mathrm{L}$ (SD: $\pm 104.7 \mathrm{mg} / \mathrm{L}) \mathrm{M}$; D-dimer, 8,177.8 ng/mL (SD: $\pm 19,225.0 \mathrm{ng} / \mathrm{mL})$; ferritin, $1,821.1 \mu \mathrm{g} / \mathrm{mL}( \pm 2,243.4 \mu \mathrm{g} / \mathrm{mL}) ;$ fibrinogen, $6.5 \mathrm{~g} / \mathrm{L}( \pm 2.1 \mathrm{~g} / \mathrm{L})$ and lactate dehydrogenase $525.0 \mathrm{U} / \mathrm{L}( \pm 468.2$ $\mathrm{U} / \mathrm{L})$. A detailed description of biochemical findings is presented in Figure 1. 
Table 1. Patient demographics and tumour characteristics.

\begin{tabular}{|c|c|c|c|c|}
\hline \multirow[t]{2}{*}{ Characteristics } & All patients $(N=100)$ & $\begin{array}{l}\text { Haematological malignancies } \\
\qquad(n=37)\end{array}$ & Solid tumours $(n=44)$ & $\begin{array}{l}\text { Paediatric patients } \\
\qquad(n=19)\end{array}$ \\
\hline & $N(\%)$ & $n(\%)$ & $n(\%)$ & $n(\%)$ \\
\hline $\begin{array}{l}\text { Age } \\
\text { Mean }( \pm S D)\end{array}$ & $43.5(24.8)$ & 49 (17.9) & $55.3(18)$ & $5.2(4.3)$ \\
\hline $\begin{array}{l}\text { Age groups } \\
\begin{array}{l}<15 \\
15-20 \\
21-30 \\
31-40 \\
41-50 \\
51-60 \\
61-70 \\
>70\end{array}\end{array}$ & $\begin{array}{c}19(19) \\
8(8) \\
5(5) \\
6(6) \\
16(16) \\
10(10) \\
22(22) \\
14(14)\end{array}$ & $\begin{array}{c}0 \\
5(13.5) \\
1(2.7) \\
5(13.5) \\
8(21.6) \\
6(16.2) \\
8(21.6) \\
4(10.8)\end{array}$ & $\begin{array}{c}0 \\
3(6.8) \\
4(9.1) \\
1(2.3) \\
8(18.2) \\
4(9.1) \\
14(31.8) \\
10(22.7)\end{array}$ & $\begin{array}{c}19(100.0) \\
0 \\
0 \\
0 \\
0 \\
0 \\
0 \\
0\end{array}$ \\
\hline $\begin{array}{l}\text { Sex } \\
\text { Male } \\
\text { Female }\end{array}$ & $\begin{array}{l}57(57) \\
43(43)\end{array}$ & $\begin{array}{l}21(56.8) \\
16(43.2)\end{array}$ & $\begin{array}{l}23(52.3) \\
21(47.7)\end{array}$ & $\begin{array}{c}13(68.4) \\
6(31.6)\end{array}$ \\
\hline $\begin{array}{l}\text { Comorbidities }^{\mathrm{a}} \\
\text { None } \\
\text { Hypertension } \\
\text { Chronic lung disease } \\
\text { Obesity } \\
\text { Diabetes mellitus } \\
\text { Chronic liver disease } \\
\text { Others }\end{array}$ & $\begin{array}{c}43(43) \\
23(23) \\
10(10) \\
8(8) \\
6(6) \\
1(1) \\
34(34)\end{array}$ & $\begin{array}{c}13(35.1) \\
8(21.6) \\
6(16.2) \\
5(13.5) \\
3(8.1) \\
0 \\
15(40.5)\end{array}$ & $\begin{array}{c}21(47.7) \\
13(29.5) \\
3(6.8) \\
3(6.8) \\
3(6.8) \\
1(2.3) \\
11(25.0)\end{array}$ & $\begin{array}{c}9(47.4) \\
2(10.5) \\
1(5.3) \\
0 \\
0 \\
0 \\
8(42.1)\end{array}$ \\
\hline $\begin{array}{l}\text { Smoking status } \\
\text { No } \\
\text { yes }\end{array}$ & $\begin{array}{l}92(92) \\
8(8)\end{array}$ & $\begin{array}{c}33(89.2) \\
4(10.8)\end{array}$ & $\begin{array}{c}40 \text { (90.9) } \\
4(9.1)\end{array}$ & $\begin{array}{c}19(100) \\
0\end{array}$ \\
\hline $\begin{array}{l}\text { Type of cancer } \\
\text { Lymphoma } \\
\text { Multiple myeloma } \\
\text { Leukaemia } \\
\text { Breasts and soft tumours } \\
\text { Urological } \\
\text { Gastrointestinal } \\
\text { Central nervous system } \\
\text { Head and neck } \\
\text { Lung } \\
\text { Unknown primary metastasis } \\
\text { Gynaecologic } \\
\text { Osteosarcoma } \\
\text { Edwing's sarcoma } \\
\text { Hepatoblastoma } \\
\text { Wilms tumour } \\
\text { Rhabdomyosarcoma }\end{array}$ & $\begin{array}{c}19(19) \\
3(3) \\
28(28) \\
12(12) \\
12(12) \\
8(8) \\
4(4) \\
3(3) \\
2(2) \\
1(1) \\
1(1) \\
2(2) \\
2(2) \\
1(1) \\
1(1) \\
1(1)\end{array}$ & $\begin{array}{c}19 \text { (51.4) } \\
3(8.1) \\
15(40.5) \\
0 \\
0 \\
0 \\
0 \\
0 \\
0 \\
0 \\
0 \\
0 \\
0 \\
0 \\
0 \\
0\end{array}$ & $\begin{array}{c}0 \\
0 \\
0 \\
12(27.3) \\
12(27.3) \\
8(18.2) \\
3(6.8) \\
3(6.8) \\
2(4.5) \\
1(2.3) \\
1(2.3) \\
1(2.3) \\
1(2.3) \\
0 \\
0 \\
0\end{array}$ & $\begin{array}{c}0 \\
0 \\
13(65.0) \\
0 \\
0 \\
0 \\
1(5.3) \\
0 \\
0 \\
0 \\
0 \\
1(5.3) \\
1(5.3) \\
1(5.3) \\
1(5.3) \\
1(5.3)\end{array}$ \\
\hline
\end{tabular}


Table 1. Patient demographic and tumour characteristics. (Continued)

\begin{tabular}{|l|c|c|c|}
\hline $\begin{array}{l}\text { Controlled oncological disease } \\
\text { No }\end{array}$ & $72(72)$ & $28(75.7)$ & $28(63.6)$ \\
Yes & $28(28)$ & $9(24.3)$ & $16(36.4)$ \\
\hline Oncologic treatment in the last 30 days & & \\
No & & & \\
Surgery & $45(45)$ & $17(45.2)$ & $23(52.3)$ \\
Chemotherapy & $7(7)$ & $1(2.7)$ & $5(11.4)$ \\
Radiotherapy & $40(40)$ & $18(48.6)$ & $8(18.2)$ \\
Hormonotherapy & $4(4)$ & $1(2.7)$ & $3(6.8)$ \\
\hline
\end{tabular}

avariables with one or more answers

Table 2. Clinical presentation of COVID-19.

\begin{tabular}{|c|c|c|c|c|}
\hline \multirow[t]{2}{*}{ Initial clinical features } & All patients $(N=100)$ & $\begin{array}{l}\text { Haematological malignancies } \\
\qquad(n=37)\end{array}$ & Solid tumours $(n=44)$ & $\begin{array}{l}\text { Paediatric patients } \\
\qquad(n=19)\end{array}$ \\
\hline & $N(\%)$ & $n(\%)$ & $n(\%)$ & $n(\%)$ \\
\hline \multicolumn{5}{|l|}{ Initial signs and symptoms } \\
\hline Cough & $65(65)$ & $30(81.1)$ & $30(68.2)$ & $5(26.3)$ \\
\hline Fever & $57(57)$ & $23(62.2)$ & $24(54.5)$ & $10(52.6)$ \\
\hline Dyspnoea & $56(56)$ & $28(75.7)$ & $26(59.1)$ & $2(10.5)$ \\
\hline Tachypnoea & $56(56)$ & $22(59.5)$ & 27 (61.4) & $7(36.8)$ \\
\hline Fatigue & $41(41)$ & $26(70.3)$ & $14(31.8)$ & $1(5.3)$ \\
\hline Diarrhoea & $12(12)$ & $9(24.3)$ & $3(6.8)$ & 0 \\
\hline Myalgia & $9(9)$ & $4(10.8)$ & $4(9.1)$ & $1(5.3)$ \\
\hline Chest pain & $7(7)$ & $3(8.1)$ & $4(9.1)$ & 0 \\
\hline Anosmia & $2(2)$ & $2(5.4)$ & 0 & 0 \\
\hline Asymptomatic & $12(12)$ & $1(2.7)$ & $6(13.6)$ & $5(26.3)$ \\
\hline \multicolumn{5}{|l|}{ Severity } \\
\hline Mild & $32(32)$ & $8(21.6)$ & $13(29.5)$ & $11(57.9)$ \\
\hline Moderate & $33(33)$ & $16(43.2)$ & $10(22.7)$ & $7(36.8)$ \\
\hline Severe & $17(17)$ & $5(13.5)$ & $12(27.3)$ & 0 \\
\hline Critical & $18(18)$ & $8(21.6)$ & 9 (20.5) & $1(5.3)$ \\
\hline \multicolumn{5}{|l|}{ Origin of infection } \\
\hline Community & $71(71)$ & $30(81.1)$ & $38(86.4)$ & 3 (15.8) \\
\hline Nosocomial & $29(29)$ & 7 (18.9) & $6(13.6)$ & $16(84.2)$ \\
\hline \multicolumn{5}{|l|}{ CT study } \\
\hline No & $11(11)$ & $1(2.7)$ & $3(6.8)$ & $7(36.8)$ \\
\hline Yes & $89(89)$ & $36(97.3)$ & $41(93.2)$ & $12(63.2)$ \\
\hline \multicolumn{5}{|l|}{ Main finding on CT imaging } \\
\hline Normal & $7(7)$ & 4 (11.1) & 0 & $3(25)$ \\
\hline Consolidative & $29(32)$ & $13(36.1)$ & $13(31.7)$ & $3(25)$ \\
\hline Pleural effusion & $1(1)$ & 0 & $1(2.4)$ & 0 \\
\hline Nodular & $3(3)$ & $1(2.8)$ & 0 & $2(16.7)$ \\
\hline Ground glass & $49(55)$ & $18(50.0)$ & $27(65.9)$ & 4 (33.3) \\
\hline
\end{tabular}


Table 2. Clinical presentation of COVID-19. (Continued)

\begin{tabular}{|c|c|c|c|c|}
\hline \multicolumn{2}{|l|}{ Nosocomial infections } & \multirow[b]{3}{*}{$3(8.1)$} & \multirow[b]{3}{*}{$1(2.3)$} & \multirow[b]{3}{*}{$1(5.3)$} \\
\hline Blood culture & & & & \\
\hline Coagulase (-) Staphylococcus & $5(5)$ & & & \\
\hline Enterobacteria & $1(1)$ & $1(2.7)$ & 0 & 0 \\
\hline Acinetobacter baumannii & $1(1)$ & 0 & 0 & $1(5.3)$ \\
\hline C. albicans & $1(1)$ & 0 & $1(2.3)$ & 0 \\
\hline Not applicable & $92(92)$ & $33(89.2)$ & $42(95.5)$ & $17(89.5)$ \\
\hline \multicolumn{5}{|l|}{ BAL culture ${ }^{a}$} \\
\hline Klebsiella & $3(3)$ & 0 & $3(6.8)$ & 0 \\
\hline S. maltophilia & $1(1)$ & $1(2.7)$ & 0 & 0 \\
\hline Not done & $96(96)$ & $36(97.3)$ & $41(93.2)$ & $19(100.0)$ \\
\hline \multicolumn{5}{|l|}{ Urine culture ${ }^{a}$} \\
\hline C. tropicalis & $1(1)$ & $1(2.7)$ & 0 & 0 \\
\hline Enterococcus & $1(1)$ & $1(2.7)$ & 0 & 0 \\
\hline Pseudomonas & $2(2)$ & 0 & $1(2.3)$ & $1(5.3)$ \\
\hline Not done & $96(96)$ & $35(94.6)$ & $42(97.7)$ & $18(94.7)$ \\
\hline
\end{tabular}

avariables with one or more answers

\section{Treatment for COVID-19 and complications}

In total, $11 \%$ of patients required IMV while $31 \%$ required high flow of $\mathrm{O}_{2}$. Twelve percent of patients had admission to ICU (11 adults and 1 paediatric patient). The most frequent drugs indicated to COVID-19 management were enoxaparin (49\%), methylprednisolone (37\%), dexamethasone (25\%), azithromycin (12\%), ivermectin (12\%) and hydroxychloroquine (9\%). The antibiotic treatment to co-infections included piperacillin/tazobactam (60\%), meropenem (43\%) among others. Drug-related toxicities included hyperglycaemia in 54\% of patients, hypokalaemia in $4 \%$ and hyponatraemia in $1 \%$ of cases (Table 3 ).

\section{Clinical course and outcomes}

Regarding the clinical course of COVID-19, $42 \%$ of patients developed acute respiratory failure ( $50.6 \%$ in adults versus $1 \%$ in paediatrics), $19 \%$ had ARDS ( $23.5 \%$ in adults versus $0 \%$ in paediatrics), $12 \%$ had septic shock and other complications ( $14.8 \%$ in adults versus $0 \%$ in paediatrics). Forty-eight percent of patients ( $43 \%$ in adults versus $68 \%$ in paediatrics) had been discharged at the end of follow-up period (mean of hospital stay in adults, 15.9 days, SD: \pm 10.9 versus 11.9 days, SD: \pm 10.5 , in paediatric patients). Overall, the fatality rate was $39 \%, 50 \%$ in adult patients with solid tumours, $43.2 \%$ in adults with haematologic tumours and $5.3 \%$ in paediatric patients. The cause of death was ARDS in $64.1 \%$, septic shock in $20.5 \%$, multi-organ failure in $10.3 \%$, cardiorespiratory arrest in $2.6 \%$ and progression of oncological disease in $2.6 \%$ (Table 4).

\section{Discussion}

The ongoing COVID-19 pandemic has had terrible consequences to the Peruvian public health [19]. This public emergency caused the delay of treatment of patients with chronic diseases, including cancer. 


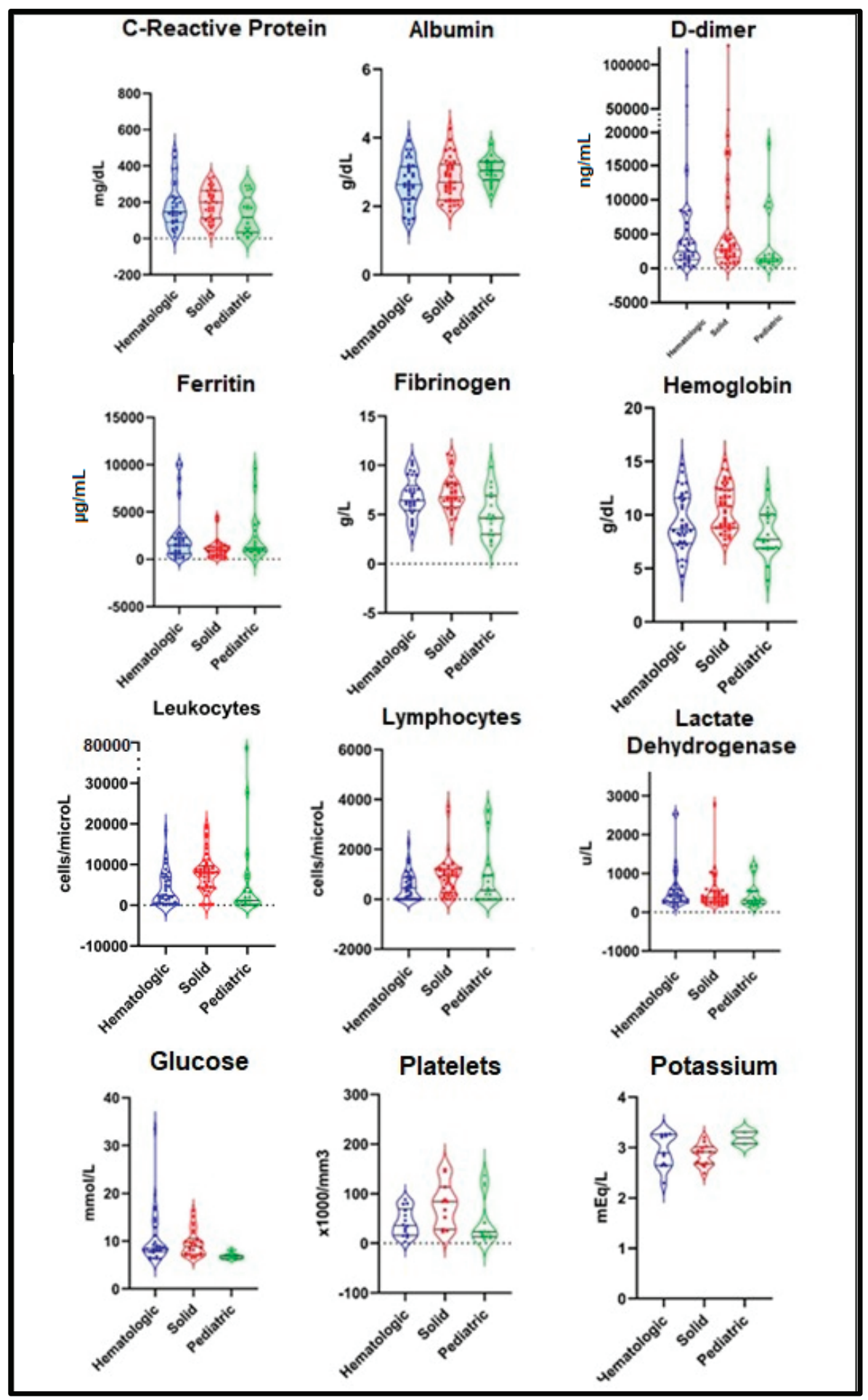

Figure 1. Main findings in laboratory parameters in patients with COVID-19 and cancer. 


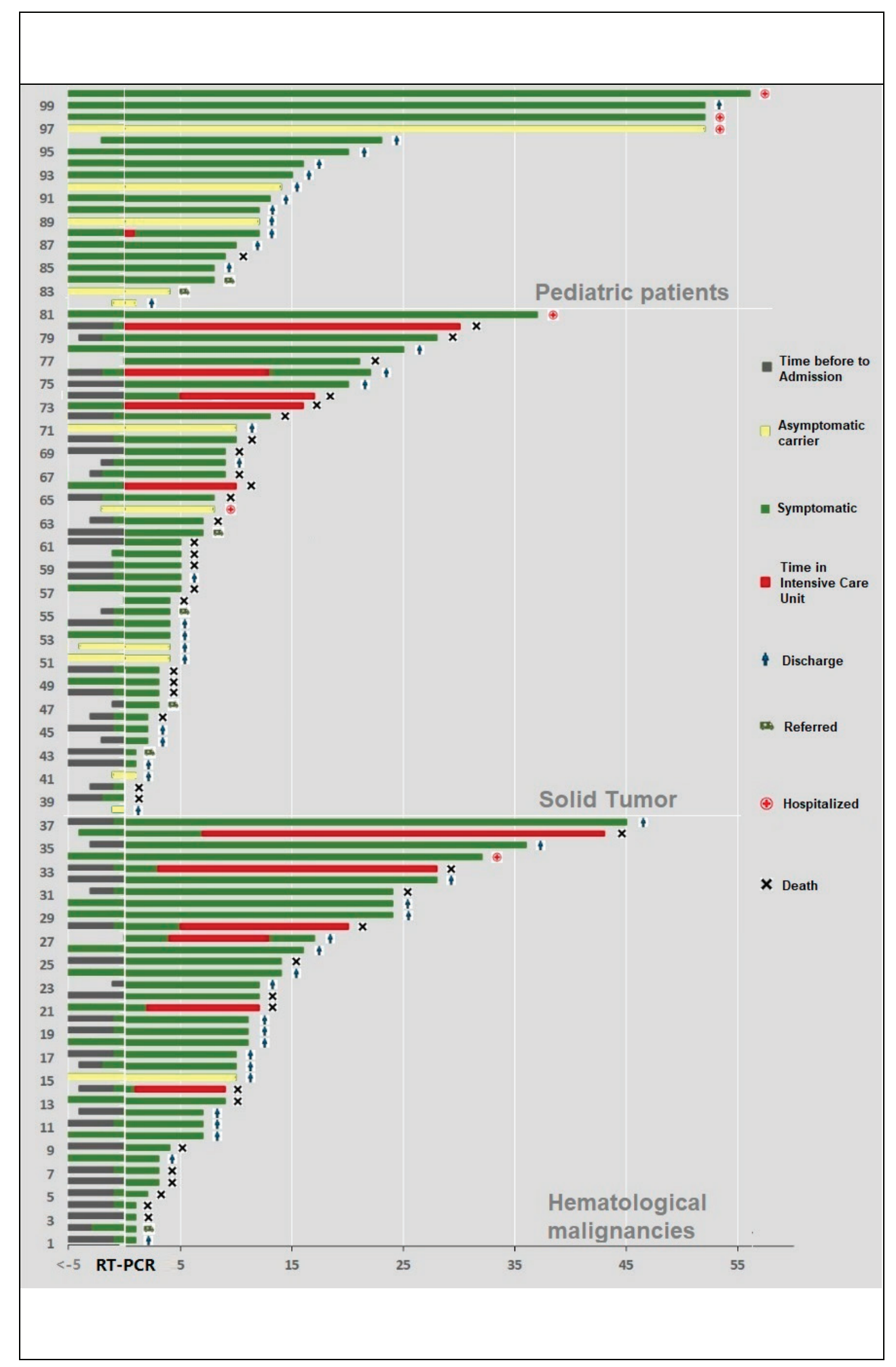

Figure 2. Timeline of the evolution of patient for type of cancer. 
Table 3. Management of COVID-19 in cancer patients.

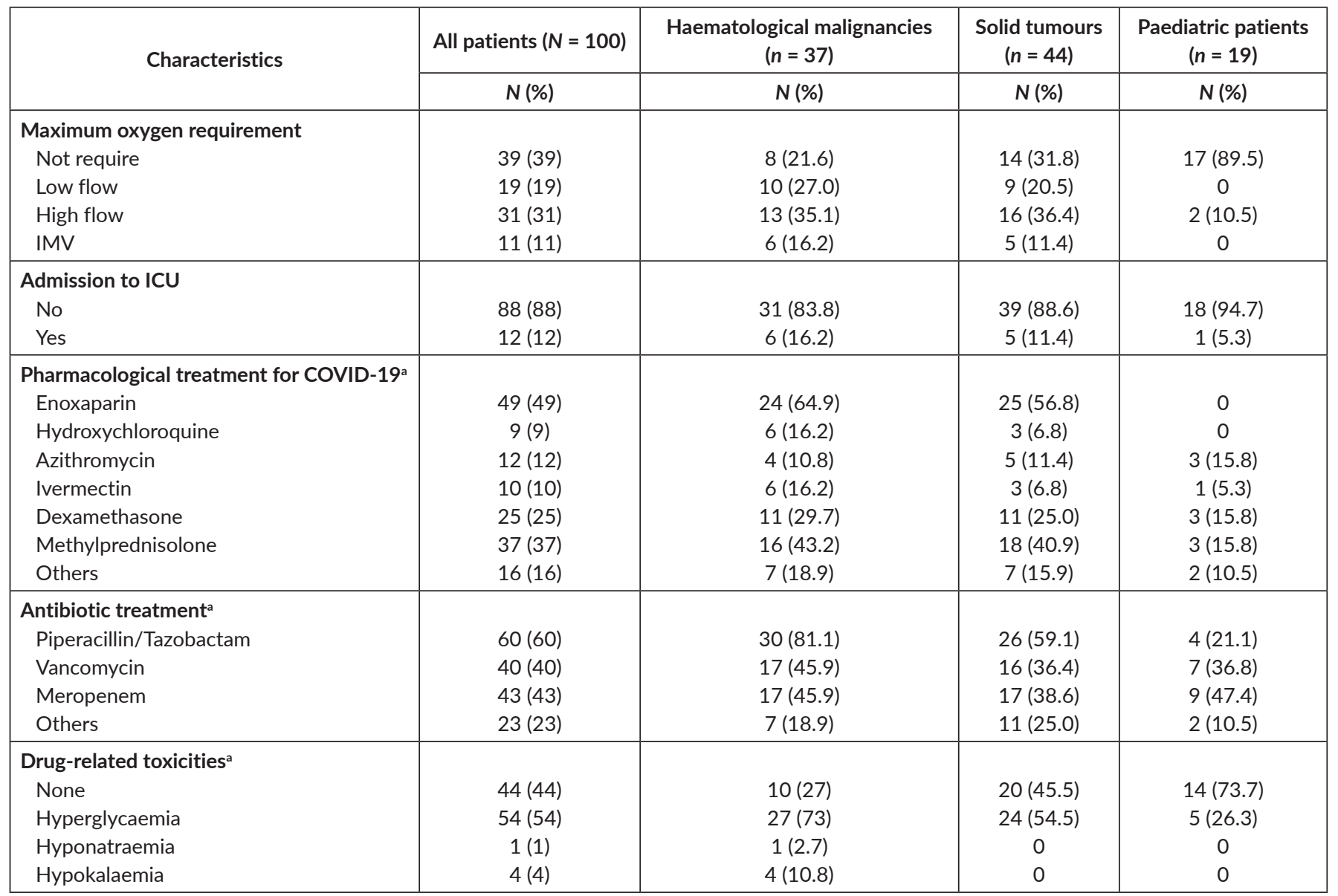

aVariables with one or more answers

Since the beginning of the pandemic, INEN established multiple actions to guarantee adequate protection for patients and healthcare personnel, while ensuring continuity of cancer care. Among these measures, we fully endorsed the recommendations of the Ministry of Health of Peru and the WHO. In order to detect early suspicious cases of COVID-19, a differentiated triage was established to identify persons under investigation and help guide initial screening tests [20, 21]. In this work, we present our experience managing cancer patients at INEN, the largest hospital for specialised cancer care in Peru. Because of the limited number of patients and events (39 deaths), we did not conduct association studies. On the other hand, the characteristics of our patients could, including inclusion of paediatric patients, lead to some differences with previous reports.

The mean age at diagnosis of COVID-19 in our patients was younger ( 43.5 years old; SD: \pm 24.8 ) than the mean age reported in other similar studies, although we included paediatric patients $[3,22,23]$. Comorbidities were present in $57 \%$ of our patients where $23 \%$ of them had hypertension. Previous report have described similar rate of comorbidities between COVID-19 patients with cancer and without cancer [10].

Haematological malignancies were the most frequent types of cancer (leukaemia and lymphoma), despite according to our epidemiology, solid tumours are most prevalent [24]. This contrast with two previous reports from China where they described lung malignancies as the most prevalent cancer among COVID-19 patients $(20 \%-25 \%)$ [3, 10]. It could be explained by the high lung cancer incidence in China [24]. In addition, comparing medical consultations between March and June of 2019 versus 2020, the department of epidemiology and statistics of INEN report a decrease of $51.6 \%$ and $79.6 \%$ in haematological and solid cancer attentions, respectively. 
Table 4. Clinical outcomes of patients diagnosed with a neoplasm and COVID-19.

\begin{tabular}{|c|c|c|c|c|}
\hline \multirow[t]{2}{*}{ Characteristics } & All patients $(N=100)$ & $\begin{array}{l}\text { Haematological malignancies } \\
\qquad(n=37)\end{array}$ & $\begin{array}{l}\text { Solid tumours } \\
\qquad(n=44)\end{array}$ & $\begin{array}{c}\text { Paediatric patients } \\
(n=19)\end{array}$ \\
\hline & $N(\%)$ & $n(\%)$ & $n(\%)$ & $n(\%)$ \\
\hline $\begin{array}{l}\text { Complications }^{\mathrm{a}} \\
\text { Acute respiratory failure } \\
\text { ARDS } \\
\text { Septic shock } \\
\text { Sepsis } \\
\text { Distributive shock } \\
\text { Acute renal failure } \\
\text { Multifactorial encephalopathy } \\
\text { Tracheostomy } \\
\text { None }\end{array}$ & $\begin{array}{l}42(42) \\
19(19) \\
12(12) \\
8(8) \\
4(4) \\
2(2) \\
2(1) \\
1(1) \\
48(48)\end{array}$ & $\begin{array}{c}20(54.1) \\
11(29.7) \\
5(13.5) \\
2(5.4) \\
3(8.1) \\
2(5.4) \\
1(2.7) \\
0 \\
13(35.1)\end{array}$ & $\begin{array}{l}21(47.7) \\
8(18.2) \\
7(15.9) \\
6(13.6) \\
1(2.3) \\
0 \\
1(2.3) \\
1(2.3) \\
17(38.6)\end{array}$ & $\begin{array}{c}1(5.3) \\
0 \\
0 \\
0 \\
0 \\
0 \\
0 \\
0 \\
18(94.7)\end{array}$ \\
\hline $\begin{array}{l}\text { Clinical outcome } \\
\text { Discharge } \\
\text { Death } \\
\text { Referred } \\
\text { Remaining hospitalised }\end{array}$ & $\begin{array}{c}48(48) \\
39(39) \\
7(7) \\
6(6)\end{array}$ & $\begin{array}{c}19(51.4) \\
16(43.2) \\
1(2.7) \\
1(2.7)\end{array}$ & $\begin{array}{c}16(36.4) \\
22(50.0) \\
4(9.1) \\
2(4.5)\end{array}$ & $\begin{array}{c}13(68.4) \\
1(5.3) \\
2(10.5) \\
3(15.8)\end{array}$ \\
\hline $\begin{array}{l}\text { Days to discharge } \\
\text { Mean }( \pm S D)\end{array}$ & 13(10.9) & $15.8(10.7)$ & $7.2(7.6)$ & $15.9(11.6)$ \\
\hline Fatality rate & $39 \%$ & $43.2 \%$ & $50.0 \%$ & $5.3 \%$ \\
\hline $\begin{array}{l}\text { Cause of death } \\
\text { ARDS } \\
\text { Septic shock } \\
\text { Multi-organ failure } \\
\text { Cardiorespiratory arrest } \\
\text { Progression of oncological disease }\end{array}$ & $\begin{array}{c}25(64.1) \\
8(20.5) \\
4(10.3) \\
1(2.6) \\
1(2.6)\end{array}$ & $\begin{array}{c}12(75) \\
3(18.8) \\
0 \\
1(6.3) \\
0\end{array}$ & $\begin{array}{c}12(54.5) \\
5(22.7) \\
4(18.2) \\
1(5) \\
1(4.5)\end{array}$ & $\begin{array}{c}1(100) \\
0 \\
0 \\
0 \\
0\end{array}$ \\
\hline
\end{tabular}

avariables with one or more answers

Cough was the most common symptom at the COVID-19 setting in our patients. This differs from the reviewed studies, in which fever was seen as the most common symptom on admission both in patients with (94\%) or without (82.1\%) cancer [25]. It could be explained by the considerable percentage of asymptomatic patients that was described in our study (12\%).

Overall, $29 \%$ of patients had nosocomial SARS-CoV-2 infection. Interestingly, while $\approx 80 \%$ of adults acquired the COVID-19 in the community, more than $80 \%$ of paediatric patients were infected in the hospital. Our Institutional policy for hospitalised paediatric patients is the joint accommodations of the patients with their guardian. The parents could have ad libitum access. Nosocomial transmission of COVID-19 among non-cancer patients only represents $1.49 \%$ of infections [10]. Previous reports in cancer patients show nosocomial infection rates of $19 \%-28.6 \%[3,10]$.

Our rate of patients admitted to ICU was low (10.48\%). As Institutional protocol, initiation of best supportive care and less invasive care measures were encouraged for patients with baseline uncontrolled disease or advanced clinical stages, which was based on utilitarian principlism due to scarcity of ICU beds. This de-escalation approach could explain the difference in the ICU admission rate compared to other international publications (7\%-21.4\%) [3, 10, 26]. 
Management guidelines for COVID-19 have been continuously changing during the pandemic. Until 4 of July, the WHO no longer recommends the use of hydroxychloroquine [16, 27]; before this recommendation, it was administered to $9 \%$ of our patients as prophylaxis. The use of enoxaparin is recommended as prophylaxis for deep vein thrombosis and was given to a half of our patients [16, 27]. Systemic anticoagulation was not administered to our paediatric patients as the WHO does not recommend it [16, 27]. The RECOVERY trial showed that the use of systemic corticosteroids reduces mortality up to a third of patients with respiratory complications during the hyperinflammatory phase $[27,28]$. In our cohort, dexamethasone was used in $25 \%$ of patients, methylprednisolone in $37 \%$ and other corticosteroids in $16 \%$ of cases, including prednisone and hydrocortisone. On 16 June 2020, the University of Oxford announced the positive effects of the use of dexamethasone, being close to the end of data collection [28].

More than half of our patients (52\%) developed complications, highlighting acute respiratory failure (42\%), ARDS (19\%) and septic shock (12\%). On the other hand, we had a higher mortality rate in comparison to other similar studies $(11.43 \%-28.6 \%)[3,10,26]$. It should be noted that in our cohort, we had a $72 \%$ of patients with uncontrolled oncological disease; in addition, mortality in patients admitted to ICU was $75 \%$.

Patients who have received prior cancer treatment are more susceptible to infection than patients without cancer. Patients treated with surgery and chemotherapy have five times higher risk of a severe clinical event than those who did not receive any treatment [29]. In our study, $30.9 \%$ of the patients who received cancer treatment died. This could differ from previously mentioned study, the mortality rate found in patients that received chemotherapy $(25 \%)$ or had surgery $(28.6 \%)$ was lower than the fatality rate. On the other hand, the mortality rate of patients that did not receive cancer treatment in the last 30 days was $48.5 \%$. Prospective and well-powered studies and meta-analysis of observational studies have not related the type of treatment with mortality by COVID-19 in cancer patients [26, 30].

\section{Conclusion}

In conclusion, paediatric patients had a lower mortality rate than adult populations and a higher number of asymptomatic carriers, early diagnosis and continuous testing in this group are recommended. In addition, strict protocols are encouraged to avoid intrahospitalary infections. Finally, considering oncological treatments 30 days before COVID-19 diagnosis, our data did not reveal an increased mortality, similar to worldwide publications. Conversely, they had lower mortality rates than the rest of the patients.

\section{Conflicts of interest}

The authors declare that they have no conflict of interests with this research.

\section{Funding}

None.

\section{References}

1. World Health Organization (2020) Events as They Happen (Geneva: World Health Organization)

2. Sohrabi C, Alsafi Z, and Neill NO, et al (2020) World Health Organization declares global emergency: a review of the 2019 novel coronavirus (COVID-19) Int J Surg 76 71-76

3. Zhang L, Zhu F, and Xie L, et al (2020) Clinical characteristics of COVID-19-infected cancer patients : a retrospective case study in three hospitals within Wuhan, China Ann Oncol 31(7) 894-901 
4. Coronaviridae Study Group of the International Committee on Taxonomy of Viruses (2020) The species Severe acute respiratory syndrome-related coronavirus: classifying 2019-nCoV and naming it SARS-CoV-2 Nat Microbiol 5 536-544 [http://www.ncbi.nlm.nih.gov/ pubmed/32123347] Date accessed: 16/03/20

5. Coronavirus disease (COVID-19) [https://www.who.int/emergencies/diseases/novel-coronavirus-2019] Date accessed: 25/10/20

6. Rodriguez-morales AJ, Pérez-díaz CE, and Villamil-gómez WE, et al (2020) Preparación y control de la enfermedad por coronavirus 2019 (COVID-19) en América Latina Acta Med Peru 37(1) 3-7

7. Rentería ER, Cespedes P, and Cerna K, et al (2020) Epidemiologic patterns of COVID-19 incidence in the Province of Lima Ann Epidemiol $5427-28$

8. Ministerio de salud (2020) Sala Situacional COVID-19 Peru (Ministerio de salud)

9. Liang W, Guan W, and Chen R, et al (2020) Cancer patients in SARS-CoV-2 infection: a nationwide analysis in China Lancet Oncol 21(3) 335-337 https://doi.org/10.1016/S1470-2045(20)30096-6 Date accessed: 18/10/20

10. Dai M, Liu D, and Liu M, et al (2020) Patients with cancer appear more vulnerable to SARS-COV-2: a multicenter study during the COVID-19 outbreak Cancer Discov 10(6) 783-791

11. Kong X, Qi Y, and Huang J, et al (2021) Epidemiological and clinical characteristics of cancer patients with COVID-19: a systematic review and meta-analysis of global data Cancer Lett 508 30-46

12. Gosain R, Abdou Y, and Singh A, et al (2020) COVID-19 and cancer : a comprehensive review Curr Oncol Rep 22(53) 1-15

13. Yu J, Ouyang W, and Chua MLK, et al (2020) SARS-CoV-2 transmission in patients with cancer at a tertiary care hospital in Wuhan, China JAMA Oncol 6(7) 1108-1110

14. Liu T, Zeng G, and Tao H, et al (2020) Low prevalence of IgG antibodies to SARS-CoV-2 in cancer patients with COVID-19 Int J Cancer 147(11) 3267-3269 https://doi.org/10.1002/ijc.33148 Date accessed: 25/10/20

15. Elkrief A, Desilets A, and Papneja N, et al (2020) High mortality among hospital-acquired COVID-19 infection in patients with cancer: a multicentre observational cohort study Eur J Cancer 139 181-187

16. World Health Organization (2020) Clinical Management of COVID-19: Interim Guidance (Geneva: World Health Organization)

17. Wang D, Hu B, and Hu C, et al (2020) Clinical characteristics of 138 hospitalized patients with 2019 novel coronavirus-infected pneumonia in Wuhan, China JAMA 323(11) 1061-1069

18. Bernheim A, Mei X, and Huang M, et al (2020) Chest CT findings in coronavirus disease-19 (COVID-19): relationship to duration of infection Radiology 295(3) 200463

19. Neyra-León J, Huancahuari-Nuñez J, and Díaz-Monge JC, et al (2020) The impact of COVID-19 in the healthcare workforce in Peru J Public Health Policy 1-3 [http://link.springer.com/10.1057/s41271-020-00259-6] Date accessed: 18/10/20

20. Instituto Nacional de Enfermedades Neoplasicas (2020) Documento Técnico- Recomendaciones Para la Prevención, Atención y Manejo de Pacientes Oncológicos Durante la Pandemia del COVID-19 (Surquillo: Instituto Nacional de Enfermedades Neoplasicas) pp 1-93

21. Instituto Nacional de Enfermedades Neoplasicas (2020) Plan de Contingencia Frente al Coronavirus COVID-19 (Surquillo: Instituto Nacional de Enfermedades Neoplasicas) pp 1-51

22. Elkrief A, Desilets A, and Papneja N, et al (2020) High mortality among hospital-acquired COVID-19 infection in patients with cancer: a multicentre observational cohort study Eur J Cancer 139 181-187 [https://pubmed.ncbi.nlm.nih.gov/33035991/] Date accessed: $18 / 10 / 20$ 
23. Bonanad C, García-Blas S, and Tarazona-Santabalbina F, et al (2020) The effect of age on mortality in patients with COVID-19: a metaanalysis with 611,583 subjects J Am Med Dir Assoc 21(7) 915-918

24. World Health Organization (2018) Cancer Today (Geneva: World Health Organization)

25. Ramanathan K, Antognini D, and Combes A, et al (2020) Clinical course and risk factors for mortality of adult inpatients with COVID-19 in Wuhan, China: a retrospective cohort study Lancet 395(10229) 1054-1062

26. Lee LYW, Cazier JB, and Starkey T, et al (2020) COVID-19 mortality in patients with cancer on chemotherapy or other anticancer treatments: a prospective cohort study Lancet 395(10241) 1919-1926

27. National Institute of Health (2020) COVID-19 Treatment Guidelines. Management of Persons with COVID-19 (Bethesda: National Institute of Health)

28. Oxford University (2020) Low-Cost Dexamethasone Reduces Death by Up to One Third in Hospitalised Patients with Severe Respiratory Complications of COVID-19 (Oxford: Oxford University) 2020

29. Landman A, Feetham L and Stuckey D (2020) Cancer patients in SARS-CoV-2 infection: a nationwide analysis in China Lancet Oncol 2045(20) 335-337

30. Liu Y, Lu H, and Wang W, et al (2021) Clinical risk factors for mortality in patients with cancer and COVID-19: a systematic review and meta-analysis of recent observational studies Expert Rev Anticancer Ther [Internet] 21(1):107-19 https://doi.org/10.1080/14737140.20 21.1837628 Date accessed: 21/04/21 